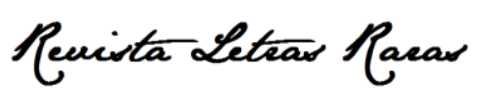

ISSN: $2317-2347$ - v. 10, n. 4 (2021)

Todo o conteúdo da RLR está licenciado sob Creative Commons Atribuição 4.0 Internacional

\title{
O humor como estratégia pedagógica: um breve balanço /
}

\section{Humor as a pedagogical strategy: a short review}

\section{Silvia Ines Coneglian Carrilho de Vasconcelos*}

Doutora em Linguística Aplicada e Estudos da Linguagem pela PUC/SP, possui pós-doutorado em Linguística Aplicada (UNICAMP) e em Letras (UPM). Atualmente é professora da Universidade Federal de Santa Catarina no PROFLETRAS, atuando principalmente nos seguintes temas: discurso, mídia, humor, jogos pedagógicos, ensino, escrita acadêmica, análise e produção de material didático e ensino de português como língua materna e não materna.

(iD) https://orcid.org/0000-0001-9474-0656

\section{Érica Milani Dellai*}

Graduanda em Letras Português na Universidade Federal de Santa Catarina, participou como voluntária de Iniciação Científica no projeto "O Humor como dispositivo didático-pedagógico para o ensino de línguas". Atualmente faz parte do projeto "Formação continuada para professores Rikbaktsa" e do projeto de pesquisa intitulado "Indefiniteness across languages" onde estuda a língua Rikbaktsa (Macro-Jê).

iD https://orcid.org/0000-0003-4773-5509

Recebido em: 08 fev. 2021. Aprovado em: 20 out. 2021.

\section{Como citar este artigo:}

VASCONCELOS, Silvia Ines Coneglian Carrilho de; DELLAl, Érica Milani. O humor como estratégia pedagógica: um breve balanço. Revista Letras Raras. Campina Grande, v. 10, n. 4, p. 181-203, dez. 2021.

\section{RESUMO}

São muitos os trabalhos teóricos que buscam refletir sobre as práticas pedagógicas de professores. Dentre eles, é frequente a indicação tanto de problemas de concentração quanto de motivação dos alunos em sala, na maioria das vezes causa e consequência de aulas monótonas que acabam não produzindo um bom rendimento do conteúdo disciplinar desenvolvido. Em vista disso, educadores buscam novas formas de tornar as aulas mais agradáveis e dinâmicas com a presença do humor como umas das estratégias frequentemente estudadas. Entretanto, o humor ainda é motivo de discussão dadas as diversas problemáticas que o envolvem e também a forma pela qual é abordado dentro de sala de aula. Para buscar responder à demanda do uso do humor em sala de aula, foi desenvolvida uma pesquisa bibliográfica centrada no levantamento de contribuições de autores (ABU BAKAR, 2018; BENEDICTO, 2013; ENGRÁCIO, 2008; JOSÉ, 2008; MARLOW, 2017; OTTONI, 2007; SANTOS, 2010; SOUSA, 2016) que vêm estudando esse tema, sua problemática e sua aplicabilidade a diferentes disciplinas a fim de tecer um panorama do assunto que possa servir de base a pesquisas futuras. Durante a pesquisa, verificou-se que essa estratégia, se bem empregada, é bastante benéfica para o estreitamento de vínculos entre aluno e professor, para a efetivação da aprendizagem ou

*

silviaconeglian@gmail.com

**

ericamdellai@gmail.com 


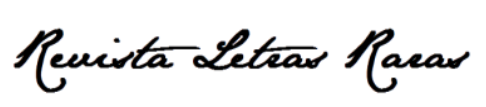

ISSN: 2317-2347 - v. 10, n. 4 (2021)

Todo o conteúdo da RLR está licenciado sob Creative Commons Atribuição 4.0 Internacional

simplesmente para um alívio da tensão dentro de sala de aula. Além disso, também é bastante aceita pelos alunos. No entanto, há que se atentar para os limites de seu uso em atividades pedagógicas.

PALAVRAS-CHAVE: Ensino, Humor, Escola.

\title{
ABSTRACT
}

Several theoretical research works discuss teachers' pedagogical practices, among which there are frequent intimations of lack of students' concentration and stimulation in the classroom. They are mostly the cause and consequence of boring lessons which do not yield results as from the contents of the subject matter developed. Educators strive for new methods for more agreeable and dynamic lessons. Humor may be one of the strategies that has been discussed and analyzed. However, humor is still a cause of discussions due to several issues involved and to the mode it is addressed within the classroom. A bibliographic survey has been developed to approach the use of humor in the classroom. Research comprised the contribution of authors (ABU BAKAR, 2018; BENEDICTO, 2013; ENGRÁCIO, 2008; JOSÉ, 2008; MARLOW, 2017; OTTONI, 2007; SANTOS, 2010; SOUSA, 2016) who studied the theme, its problems and applicability within the different disciplines to have a general view on the matter and which may foreground further research. It has been observed during the process that the strategy, if worked out properly, is beneficent for bonding between student and teacher, efficient learning, letting off steam within the classroom. It is also highly appreciated by students. Care must be taken not to go beyond the limits in pedagogical activities KEYWORDS: Teaching; Humor; School.

\section{Introdução}

\begin{abstract}
A pessoa que ri se poupa, de alguma forma, e ela ri por isso, ao passo que o homem triste se enfraquece (MINOIS, 2003, p. 527).
\end{abstract}

Os benefícios do humor para a saúde não são novidades. Muitas pesquisas foram realizadas, as quais buscaram analisar os impactos que o divertido, o lúdico, o cômico, o riso e 0 engraçado causam nas pessoas. Luís de Sousa (2016) afirma que o humor pode aliviar tensões, libertar sentimentos de raiva, ajudar a lidar com sentimentos dolorosos, além de contribuir para a manutenção da saúde. Pesquisas realizadas em 2001 e 2007, por exemplo, confirmam que 0 humor gera benefícios tanto para o sistema imunológico quanto para o sistema cardiovascular (SOUSA, 2016). Esses benefícios são frequentemente explorados em hospitais pelos Enfermeiros da Alegria:

Dado que o humor ajuda a lidar com os constrangimentos da vida e que os enfermeiros são os profissionais que mais lidam com a tensão, sofrimento, perda e medo, é compreensivel que sejam estes os que mais se têm preocupado em estudar o humor, de forma a aumentar o conhecimento e a tornar possível aperfeiçoar o seu uso, no contexto dos cuidados de saúde em geral e de enfermagem em particular. (JOSÉ, 2008, p. 24).

Além disso, a psicóloga Emma Otta (1994, p. 34 apud SILVA; CAMPOS, 2014, p. 3) afirma que "o riso transforma-se num mecanismo importante para promover o desenvolvimento cognitivo e emocional". Ademais, colabora, também, com a aprendizagem, conforme Souza (2016). Em 


\section{Penista Letras Parar}

ISSN: 2317-2347 - v. 10, n. 4 (2021)

Todo o conteúdo da RLR está licenciado sob Creative Commons Atribuição 4.0 Internacional

vista disso, por que são os enfermeiros os que ainda mais têm se preocupado em estudar o humor quando vemos tantos indícios de sua ajuda na manutenção tanto da saúde física quanto no desenvolvimento cognitivo? Quais são os estudos que estão sendo feitos sobre esse assunto no campo da pedagogia?

Dentro das salas de aula é comum ouvir queixas de professores dizendo que se sentem desestimulados a dar aula visto que os alunos não apresentam interesse nas disciplinas que ministram, que o comportamento imaturo destas dá margem a "gracinhas" que desviam o foco da aula para assuntos paralelos e que esse comportamento compromete 0 aproveitamento da aula e impacta negativamente as avaliações. Além disso, a desmotivação dos professores para preparar suas aulas, principalmente em decorrência de jornadas exaustivas, faz com que a forma pela qual o conteúdo é abordado em sala seja desenvolvido de maneira monótona, quase como um monólogo no clássico formato "discurso-fileiras-quadro-giz". Como consequência, o professor acaba muitas vezes não conseguindo desenvolver no aluno a percepção do "o quê" e do "como" está sendo ensinado pode ter relevância para sua vida.

Em vista disso, uma pergunta se faz pertinente: por que não lançar mão do humor dentro da sala de aula? Muitos educadores buscam pesquisar e desenvolver formas alternativas de ensino que aproveitem o humor (já presente em sala e frequentemente causa de dispersão), como uma estratégia para manter os estudantes concentrados e atentos. É notável que rir nos cause prazer e que atividades desenvolvidas com prazer tendem a apresentar mais rendimentos. Porém, foi de interesse da pesquisa, aqui relatada, indicar também os limites dentro do qual o humor pode atuar como participante secundário, sem desviar o foco do conteúdo a ser trabalhado. É ainda importante ressaltar aqui que este balanço temático não pretende restringir humor apenas como 0 ato de "dar gargalhadas" frente a uma situação apresentada de forma cômica pelo professor, mas também apontar pequenos gestos, estratégias e práticas dentro da sala de aula que possam torná-la um ambiente mais alegre e descontraído sem que se perca o objetivo primário da aula.

Considerando que uma análise do humor como estratégia de ensino ainda não seja facilmente encontrada em manuais sobre educação e que informações sobre essa temática se encontrem, em geral, disponíveis apenas em teses, dissertações e artigos acadêmicos (muitos ainda bastante recentes), fez-se necessário um estudo que organizasse sucintamente uma revisão 


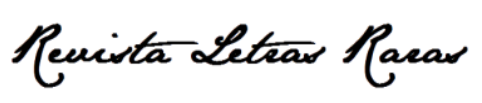

ISSN: $2317-2347$ - V. 10, n. 4 (2021)

Todo o conteúdo da RLR está licenciado sob Creative Commons Atribuição 4.0 Internacional

de literatura, no formato de um balanço teórico sobre o que já há de material publicado, a fim de nortear educadores e pesquisadores que queiram começar a pesquisar mais profundamente sobre o tema.

\section{Contextualizações iniciais}

\subsection{A pedagogia ao longo dos anos}

É difícil tentar resumir a história da pedagogia ao longo dos anos a fim de dar um panorama de sua evolução. Francisco Larroyo (1974) propõe fazer sua divisão em períodos mais específicos e limitados, diferentemente dos períodos demasiadamente amplos e gerais estabelecidos pela história. Em sua divisão, Larroyo (1974) estabelece dez períodos, dentre os quais podem-se destacar os povos clássicos, a educação cristocêntrica, a pedagogia do Renascimento, o realismo pedagógico, a pedagogia do século XIX, dentre outros períodos sobre os quais discorre em sua obra. Cronologicamente, o período que inicia a história da pedagogia remete-se à educação pré-histórica. Esse período é denominado por ele de "época do tradicionalismo", na qual o ideal da educação era transmitir os costumes e tradições do passado por meio de ações no presente. Maria Lúcia de Arruda Aranha (2006) também se refere à educação do período pré-histórico como uma educação tradicional, mas amplia sua caracterização apontando para as relações de proximidade entre os membros de um grupo. 0 processo de ensinar e aprender se definia pela ação do fazer junto. Tanto em Larroyo quanto em Aranha, não há menção de como essas relações ocorriam efetivamente. Não se pode dizer, portanto, se 0 humor estaria presente como estratégia pedagógica.

Posteriormente, na Antiguidade clássica, a noção de pedagogia e de ensino começa a se estruturar a partir de filósofos, tais como Demócrito, Sócrates, Aristóteles e Platão. "O ensino tornase então uma disciplina, e a ideia de mestre/aluno ganha forma" (ENGRÁCIO, 2008, p. 9). A paideia (inicialmente com o significado de educação das crianças) tinha a educação como um fenômeno integral, voltado tanto para o cultivo do corpo como para alma, compondo-se, assim, pela ginástica (conjunto de exercícios físicos) e pela música (que compreendia a formação espiritual, tal como educação estética, moral e religiosa). Aranha (2006) esclarece que a proposta pedagógica aristotélica estava fundada no cultivo da virtude a partir da disciplina conseguida pela repetição do modelo a ser seguido e do padrão a ser alcançado. Embora repetição de modelo e disciplina não descartem, a priori, o uso do humor nas relações de ensino-aprendizagem, é certo 


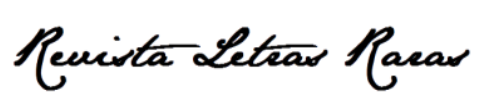

ISSN: 2317-2347 - v. 10, n. 4 (2021)

Todo o conteúdo da RLR está licenciado sob Creative Commons Atribuição 4.0 Internacional

que, pelo menos, Sócrates - depreensível a partir dos diálogos de Platão - lançava mão de tiradas humorísticas com o intuito de fazer o discípulo pensar.

No ocidente, durante a Idade Média, tem início a construção da corrente pedagógica centrada na figura de Cristo, fato este que, segundo Larroyo (1974), mudou o rumo da educação no mundo ocidental.

A Idade Média, com as suas sociedades perfeitamente divididas, dava à nobreza a função bélica, ao clero a educação e ao povo o trabalho. A forma rígida da pedagogia de então estabelecia uma dicotomia visível entre aluno $\mathrm{e}$ professor ao mesmo tempo que delimitava de forma evidente o conteúdo das disciplinas leccionadas. Era um ensino muito localizado destinado essencialmente ao clero e a um conjunto de poucos favorecidos. (ENGRÁCIO, 2008, p. 9)

Aranha (2006) prefere considerar que o período medieval foi muito longo para descrevêlo por uma única característica "sem incorrer no risco da simplificação" (p. 154). Nesse sentido, aponta que foram mil anos de avanços e retrocessos com influências múltiplas de árabes, bizantinos, invasões bárbaras. Tudo isso demandou modos de produzir conhecimentos para sobrevivência bem como de propor formas de desenvolver o ensino. Ainda que não haja menção do uso do humor nas práticas pedagógica - até porque estavam pautadas pela rigidez da hierarquia que exigia disciplina férrea - há muitos registros de obras cômicas ou humorísticas escritas e encenadas em teatros populares como também nas comemorações carnavalescas. Nessas, a inversão dos papeis - os servos com performance de reis e nobres - servia de mote para enxovalhar a aristocracia (BAKHTIN, 1999).

Ecoando os movimentos da Reforma e da Contrarreforma, desenvolve-se uma pedagogia cujos protagonistas são os jesuítas com sua pedagogia eclesiástica.

Ignácio Loyola funda aquelas que serão mais tarde as bases da Pedagogia Tradicional, cujos princípios assentam sobretudo no rigor e disciplina e na impossibilidade de colocar em questão a autoridade dos professores. Numa época em que o cristianismo vivia uma separação, a autoridade não podia ser descurada na medida em que a Igreja fiel ao Papa necessitava de poder. (ENGRÁCIO, 2008, p. 10)

É no período do Renascimento que ganha força uma pedagogia de renovação humanista. A grande contribuição é de Comenius para quem o ponto central era ensinar tudo a todos. Engrácio esclarece:

Comenius estabelece os fundamentos do ensino elaborando um sistema educativo integral com uma fundamentação lógica. A junção teórico-prática como forma de facilitar a aprendizagem foi também um importante contributo daquele que é considerado o pai da Didáctica. (ENGRÁCIO, 2008, p. 9-10)

A partir do século XVII, a América - devido à invasão europeia e ao início de sua exploração colonial - também passa a fazer parte da História geral da pedagogia, uma vez que 


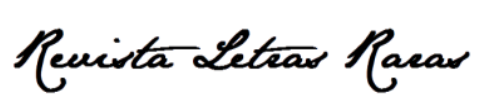

ISSN: 2317-2347 - v. 10, n. 4 (2021)

Todo o conteúdo da RLR está licenciado sob Creative Commons Atribuição 4.0 Internacional

tem de lidar com os jesuítas e suas tentativas de catequizar os povos nativos como uma forma de "expandir a fé cristã", impondo sua cultura e pensamento sobre os povos. Há um movimento de aproximação do saber do aprendente por parte do professor como ilustrado pelas práticas jesuíticas no Brasil que se davam em língua geral, e não em latim, a transmissão da fé cristã, até a dissolução dessa prática pela Reforma Pombalina (ARANHA, 2006).

Com a Revolução Industrial, tem-se uma espécie de capitalização da teoria e das práticas educacionais (LARROYO, 1974). É na Europa dessa época que começam a ser criadas as escolas públicas, surgindo como uma forma de educar as grandes massas que necessitavam de maior instrução e conhecimentos mínimos para aperfeiçoar suas funções como operários nas fábricas em desenvolvimento. A mera memorização de informações passa a ser o mais importante especialmente para os operários que deveriam executar serviços automatizados (ARANHA, 2006) Portanto, o conhecimento repassado é tido como uma verdade que não deve ser nunca questionada. "Numa sociedade em que o conhecimento dos mecanismos de aprendizagem e de desenvolvimento cognitivo ainda não haviam sido levados em conta, a relação professor-aluno era uma metáfora da relação patrão-empregado com total autoridade para o primeiro." (ENGRÁCIO, 2008, p. 10).

A partir das ideias do lluminismo tem-se um aumento na quantidade de filósofos e estudiosos que buscam uma nova forma de construir e de desenvolver os moldes da educação, tais como Rousseau, Hobbes, Locke, Dewey, dentre muitos outros. Sobre o desenvolvimento da educação no Brasil, Bruno Lima (2017) discorre:

Desde o início da história da educação, há uma busca constante pelos métodos didáticos para inovar o conhecimento que se intensificou a partir dos primeiros anos da República. E com a chegada do período de 1930 até 1960 , houve um momento crucial na educação, pois nesse período foi criado 0 Ministério da Educação e Saúde Pública. Podemos perceber que a reforma foi feita na parte educacional, mas não modificou substancialmente 0 curso primário. $O$ que houve foi a estruturação do secundário e as condições para 0 ingresso nesse nível de ensino com a criação dos exames de admissão. Significativamente, esses exames exigiam conhecimentos que não eram dados pela escola primária, e isso contribuiu, ao mesmo tempo, para resguardar a função seletiva desenvolvida pelo ensino secundário e reforçar 0 reconhecimento da inutilidade da escola primária. (LIMA, 2017, p. 28)

Mas a necessidade de aparelhar o Estado com profissionais capacitados a gerir a máquina administrativa como também a de suprir o emergente setor comercial e industrial do país suscitou discussões que culminaram em propostas educacionais caracterizadas pelo tecnicismo.

0 investimento em reflexões sobre o processo de ensinar e de aprender foi uma constante na constituição das relações sociais, históricas e econômicas da modernidade e da 


\section{Penista Letras Parar}

ISSN: 2317-2347 - v. 10, n. 4 (2021)

Todo o conteúdo da RLR está licenciado sob Creative Commons Atribuição 4.0 Internacional

contemporaneidade. Novas metodologias são criadas, especialmente no século XX. O movimento escolanovista colocou o aluno no centro do processo de aprendizagem, esfumaçando a hierarquia antes existente: professor-aluno ressoando a relação patrão-empregado. A contribuição freireana (FREIRE, 1974; 1992) deslocou a perspectiva educacional para o aluno e para o contexto em que se dá o processo educativo e com isso foi posto em realce tanto o trabalho com conteúdos relacionados ao que faz sentido para o aluno em seu contexto imediato quanto o exercício do questionamento das verdades postas nos livros didáticos por parte do professor e por parte do aluno. Assim, o diálogo entre professor-aluno-conteúdo fica estabelecido e as relações tensas têm a possibilidade de se distenderem. Essa é uma das condições para a circulação do texto humorístico.

Finalizando esta seção, importa ressaltar que, entre as muitas teorizações ou metodologias pedagógicas, o aspecto cômico - com seus correlatos como o riso, o lúdico e o humor - foi sendo cada vez mais realçado como um fator importante a ser considerado nas relações pedagógicas e suas vantagens são evidenciadas nos próximos itens.

\subsection{0 riso}

Riso, segundo o Dicionário Michaelis (2015, on-line), caracteriza-se como "1. Ato ou efeito de rir; risada; 2. Aparência ou demonstração de alegria, de contentamento, que se caracteriza pelo conjunto de contrações dos músculos da boca e da face". Para a Enciclopédia Barsa Universal, o riso é tido como a "manifestação de um estado emocional que se refere ao momento no qual uma tensão se resolve de forma inesperada" (RISO, 2010, p. 5.258). Essas definições ligeiras, porém, não conseguem englobar a complexidade envolvida por trás dos movimentos musculares que caracterizam o riso. Os "bastidores do riso", como se pode chamar, vão muito além da anatomia humana, o que fez com que se tornasse objeto de inúmeros estudos de filósofos, historiadores, psicólogos, sociólogos e médicos desde a Antiguidade até os dias atuais, conforme Georges Minois (2003). Esse autor afirma: "não se passa uma semana sem que um livro, um artigo, um programa de rádio, um colóquio ou uma conferência trate do riso nessa ou naquela época, nesse ou naquele meio" (MINOIS, 2003, p. 15). Apesar dos inúmeros estudos, nunca é possível dar a pesquisa por finalizada. As possibilidades de estudo, de teoria, de filosofia do riso parecem ser infinitas e sempre pedem algo a mais, como aponta Minois (2013, p. 15): "Elogiamos seus méritos, suas virtudes terapêuticas, sua força corrosiva diante dos integrismos e dos fanatismos e, entretanto, mal conseguimos delimitá-lo". 


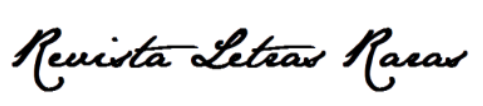

ISSN: 2317-2347 - v. 10, n. 4 (2021)

Todo o conteúdo da RLR está licenciado sob Creative Commons Atribuição 4.0 Internacional

Segundo Verena Alberti (1999), a mais antiga teoria sobre o riso vem de um trecho do diálogo Filebo. Nessa obra, Filebo, Sócrates e Protarco têm uma discussão em que Sócrates afirma ser o estado da alma que nos faz movimentar as comédias, como uma mistura de dor e prazer. Posteriormente Aristóteles desdobraria sua filosofia perpassando pelo tema e evidenciaria a marca de superioridade daquele que ri em relação ao sujeito ou objeto que é o motivo do riso. Mas, somente a partir dos romanos Cícero e Quintiliano, teorias sistemáticas sobre o riso e o risível começariam a ser formuladas. Leemen, Pinkster e Rabbie (1989 apud ALBERTI, 1999) sugerem que a ocorrência do cômico nos discursos de Cícero funciona como uma forma de divertir o leitor durante a leitura de partes mais densas. Em relação a Quintiliano, esses autores apontam que, no livro $\mathrm{VI}$, o orador romano aborda as paixões que devem estar presentes no discurso, especialmente na peroração, para suscitar o interesse no público e mobilizar as paixões. Nas palavras de Alberti (1999), o fato de Quintiliano

associar as paixões à peroração significa que, na última parte do discurso, 0 orador deve "lançar toda a sua força na batalha" e "tentar convencer o ouvinte" pela sedução de seus sentimentos. A questão do riso está, portanto, inserida na discussão sobre as paixões, sendo o risível um dos últimos recursos para convencer e seduzir o ouvinte. (ALBERTI, 1999, p. 63).

Há, portanto, aqui, o uso do humor como uma estratégia de poder no jogo político da Antiguidade.

Posteriormente, ainda de acordo com Alberti (1999), Hobbes destacaria em suas reflexões sobre a paixão as três ocasiões em que o riso acontece: quando rimos das nossas próprias ações, quando rimos das fraquezas do outro e quando rimos dos ditos ou atos engraçados, o que ecoa a proposição de Quintiliano "segundo a qual o riso se localiza em nós mesmos, nos outros e nos elementos neutros" (ALBERTI, 1999, p. 129). Alberti (1999) afirma ainda ser uma conclusão incontestável que "o objeto do riso deve ser novo e inesperado, porque uma coisa deixa de ser risível quando se torna velha ou usual". (ALBERTI, 1999, p. 128). No entanto, é preciso considerar o fato de que certos episódios, enunciados ou cenas continuam sendo risíveis por muito tempo, mesmo sendo reproduzidas ad nauseam. Isso significa que o humor que provoca o riso não necessariamente precisa ser novo. 0 importante é a aproximação de campos semânticos inusitados, como afirma Freud, a ser explicitado mais adiante.

Assumindo uma perspectiva negativa sobre o tema, Henri Bergson (1983) ganha destaque ao publicar, em 1899, três artigos na Revue de Paris, reunidos, posteriormente, na obra Le rire $(1900)^{1}$, quando "define o cômico principalmente como uma manifestação negativa, que o riso tem

1 Para esta pesquisa foi usada a seguinte edição: Bergson (1983). 


\section{Peuista Letras Paras}

ISSN: 2317-2347 - v. 10, n. 4 (2021)

Todo o conteúdo da RLR está licenciado sob Creative Commons Atribuição 4.0 Internacional

por tarefa corrigir" (ALBERTI, 1999, p. 209), sendo que, para ele, "o cômico e o riso são, respectivamente, um desvio negativo e sua sanção funcional que estabelece a ordem da vida e da sociedade". (ALBERTI, 1999, p. 209).

Outra contribuição importante é a de Freud. Para o considerado fundador da psicanálise, o chiste é a expressão do inconsciente dado que esse desconhece a proibição e se move pelo desejo. Nesse sentido, o chiste permite que o inconsciente vaze e se expresse. Para Freud (2017), o chiste, provocador da comicidade, do humor, consiste na aproximação do que está em campos distantes e inesperado. Daí, então, a explosão do riso.

Mais outras duas importantes contribuições teóricas acerca do humor, da comicidade e do riso são as de Propp (1992) e de Bakhtin (1999)2 . O primeiro retoma os conceitos de Bergson e amplifica ao incluir o riso de zombaria, que ressalta os defeitos da pessoa alvo da crítica, exemplificando em obras da literatura russa. Propp coloca em realce a teoria da comicidade das formas, das situações, das profissões a partir das personagens do mundo ficcional. Além disso estabelece a fronteira possível do que pode ser cômico. 0 segundo apresenta em seu estudo sobre cultura na Idade Média já referida anteriormente, o conceito de dessacralização de personagens consideradas como respeitáveis (os reis, por exemplo) num evento cultural em que tudo pode ser colocado de ponta cabeça: o carnaval. Nesse sentido, o fato humorístico se concretiza pelo fato de pessoas do povo, pessoas comuns se vestirem como as figuras da realeza, encenando comportamentos ridicularizados e, consequentemente, emitindo uma crítica ácida aos costumes e atitudes da época, destronando os que estão no trono. É o destronamento ou a dessacralização que gera o humor e a consequente risada.

Junto a esses, não são poucos os que se propuseram a tratar de modo sério o que faz rir: Hegel, Flögel, Schopenhauer, Kant, Jean Paul, Nietzsche, Baudelaire. E os nomes continuam. No entanto, este artigo não tem por foco se deter em cada uma dessas contribuições teóricas, limitando-se apenas a abordá-las aqui como um pano de fundo teórico que permitiu o tema humor e seus correlatos serem tema de estudo que de alguma forma serviu de subsídio às propostas de trabalho do humor como estratégia pedagógica

\footnotetext{
2 Uma abordagem mais aprofundada das contribuições de Freud, Propp e Bakhtin encontra-se em VASCONCELOS $(2019 ; 2021)$.
} 


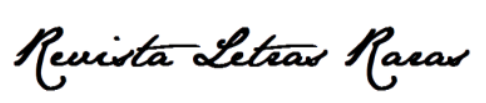

ISSN: 2317-2347 - v. 10, n. 4 (2021)

Todo o conteúdo da RLR está licenciado sob Creative Commons Atribuição 4.0 Internacional

\section{Humor no Ensino?}

Tendo em vista o que foi exposto, seria prudente, portanto, juntar o riso ao ensino? Apesar de muitos professores considerarem o humor dentro de sala de aula como um indício de algazarra e indisciplina, as pesquisas nessa área, ainda que em sua grande maioria recentes, têm se expandido. Um dos primeiros autores a trabalhar o tema do humor como estratégia pedagógica foi Avner Ziv com seu livro publicado L'humour en éducation: approche psychologique (1979). Nele, Ziv (apud ENGRÁCIO, 2008) defende que o humor pode auxiliar em processos de aprendizagem e comprova isso a partir de um experimento no qual utilizou grupos de estudantes divididos aleatoriamente em duas turmas. Enquanto uma turma assistiu às aulas com didáticas tradicionais, o outro grupo foi exposto a uma metodologia diversificada. Nesse caso, o professor se utilizou de piadas e cartuns para apresentar o conteúdo. Posteriormente os alunos fizeram uma avaliação. Os alunos do grupo de experimento tiveram um resultado consideravelmente maior do que aqueles que pertenciam ao grupo de controle (BENEDICTO, 2013). Apesar de convicto do papel colaborativo do humor na aprendizagem, Ziv destaca que as experiências realizadas nesse campo são feitas em um tempo muito curto e determinado e que acabam nada tendo "a ver com 1.000 horas de aulas que um aluno enfrenta por ano na sala de aula" (ENGRÁCIO, 2008, p. 71).

Também Erik Benedicto (2013) apresenta os aspectos positivos do uso do humor em atividades escolares e se apoia em Powell e Andresen (Humor and teaching in higher education, 1985) que também defendem os benefícios do humor para o aprendizado, acrescentando ainda que os estudantes universitários podem adquirir habilidades de utilizar o humor em sala de aula, não sendo esta uma questão apenas de ser ou não ser engraçado (POWELL; ANDRESEN, 1985 apud BENEDICTO, 2013). Erik Benedicto acrescenta um argumento a favor disso:

Lomax e Moosavi (2002) utilizaram humor oriundo de diversas fontes (como internet, revistas etc.) em aulas de estatística. Sendo que estes recursos eram sempre utilizados para abrir as aulas, e nesse caso os alunos deveriam explicar qual era o conceito relacionado à situação humorística. Com isso, os autores mostraram que foi possivel reduzir a ansiedade dos alunos, motiválos, engajá-los e aprofundar o entendimento de conceitos. (BENEDICTO, 2013, p. 29-30)

Outro pesquisador cujo trabalho é de grande destaque é o do já citado anteriormente Handerson Engrácio (2008), com sua dissertação intitulada Humor na educação. Nela, Engrácio evidencia muitas das vantagens de desenvolver aulas mais dinâmicas e descontraídas, entre as quais a criatividade e a facilidade na hora de inovar, desviando-se do pensamento padrão. Apoiase em Morrison (2008) para validar seu argumento: 


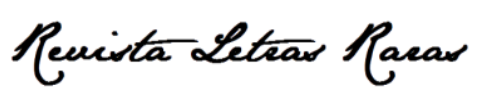

ISSN: 2317-2347 - v. 10, n. 4 (2021)

Todo o conteúdo da RLR está licenciado sob Creative Commons Atribuição 4.0 Internacional

O humor aumenta o potencial do pensamento divergente e a habilidade de resolver problemas complexos. Ligando áreas que anteriormente não estavam ligadas no cérebro, ${ }^{3}$ o humor forja novas associações envolvendo conceitos existentes. (MORRISON, 2008, p. 3 apud ENGRÁCIO, 2008, p. 81)

Engrácio (2008) ilustra a argumentação de Morrison (2008) com a seguinte anedota: Duas pulgas encontram-se à saída do cinema. Diz uma para a outra: Vamos a pé ou de cão? A comicidade ou o humor aqui residem no fato de que as pulgas são equiparadas a seres humanos e a devida adaptação (no lugar do carro tem-se o cão) é que gera o riso.

No tocante à ligação de áreas cerebrais com o prazer decorrente do riso, Alberti (1999) discorre:

Na categoria dos chistes inofensivos, Freud inclui os chistes de reflexão (Gedankenwitze) - que dizem respeito à condução do pensamento e do raciocínio - e os jogos de palavras. Em ambos, o prazer resultaria de um alívio psíquico decorrente da economia de esforço intelectual. É possível reconhecer aqui a oposição entre o riso e o pensamento sério. Nos chistes de reflexão, diz Freud, o prazer decorre da possibilidade de pensar sem as obrigações da educação intelectual, à qual estamos fadados no momento em que a razão e o julgamento crítico declaram a ausência de sentido de nossos jogos de infância. Os jogos de palavras, por sua vez, nos causam prazer porque nos dispensam do esforço necessário à utilização séria das palavras. 0 jogo de palavras suscita a ligação entre duas séries de ideias separadas, cuja apreensão usual exigiria muito mais esforço. O prazer que resulta de tal "curtocircuito" é tanto maior quanto mais as duas séries de ideias forem estranhas e afastadas entre si, o que faz com que a economia do curso do pensamento seja maior. (ALBERTI, 1999, p. 17)

Além dessa "economia de pensamento" apresentada por Freud, uma das grandes vantagens do humor em sala de aula é a construção de uma relação aluno-professor de confiança como preconizado nas propostas educativas freireanas (FREIRE, 1974; 1992) e vivamente expressas por Engrácio: "Essa maior proximidade tem a vantagem de fortalecer o trabalho de equipe e estimular os objectivos. A barreira natural entre professor e aluno é ultrapassada quando se substitui o medo pela comunicação construtiva e relaxada" (ENGRÁCIO, 2008, p. 63), sendo 0 humor uma forma de conseguir isso. Engracio (2015) acrescenta, ainda, que, por meio da criação de vínculos afetivos entre os alunos e os professores, fica muito mais fácil a colaboração e a participação do aluno nas atividades propostas pelo professor. Não é preciso ir muito longe para se chegar a esta mesma conclusão: pensando nos professores que tivemos ao longo da vida, fica fácil perceber que nos lembramos com carinho daqueles que tornaram as aulas agradáveis, instigando nossa curiosidade. É exatamente o resultado da pesquisa de Farhana Abu Bakar. Abu

\footnotetext{
${ }^{3}$ Essa constatação ressoa a proposição freudiana apresentada na seção 2 e a citação de Alberti (1999) logo a seguir.
} 


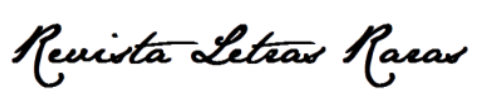

ISSN: 2317-2347 - v. 10, n. 4 (2021)

Todo o conteúdo da RLR está licenciado sob Creative Commons Atribuição 4.0 Internacional

Bakar (2018), ao apresentar em sua tese os motivos que a impulsionaram a pesquisar sobre 0 humor no ensino, diz:

Eu me lembro de frequentar aulas com muito professores. Contudo, eu gostei de apenas algumas delas. Depois de refletir, eu percebi que as aulas que eu realmente havia gostado foram ministradas por professores que introduziam 0 humor em sua explicação. ${ }^{4}$ (ABU BAKAR, 2018, p. 3, tradução nossa)

O sistema educacional que pune de maneira rígida os erros dos alunos, ou que torna as aulas maçantes e fora da realidade dos estudantes acaba sendo apenas gerador de estresse e inibidor da imaginação, da criatividade e de um pleno desenvolvimento emocional (ENGRÁCIO, 2008).

A figura do professor como alguém autoritário, detentor de todo o conhecimento e de todas as verdades do mundo foi construída ao longo de muitos anos através de um sistema educacional punitivo, moldado nas relações econômicas e culturais desde a Antiguidade e reforçadas especialmente no período medieval, que, querendo ou não, se reflete até hoje. Engrácio (2008) vê o humor também como uma forma de desenvolver atividades em sala de aula. Para esse autor, 0 professor, ao fazer piada consigo mesmo, de seus erros e suas ações, propicia ao aluno uma percepção de si mais próxima do professor, como alguém que também comete erros e que não é perfeito. $E$ isso pode aliviar a tensão circulantes nas aulas.

Engrácio, apoiando-se no conselho de Lundberg e Thurston (2002 apud ENGRÁCIO, 2008, p. 68), explicita que a admissão por parte dos professores de seus próprios erros além de rir deles faz com que os "alunos vejam que errar não é o fim do mundo". Além disso, montra que o professor não tem uma visão egocêntrica e perfeccionista de suas próprias ações. 0 humor, além de aproximar professores e alunos, se tornaria ainda uma forma de contornar situações embaraçosas ou de tensão em sala, como situações de grande irritação. "Humanizar e criar empatia é uma solução para um bom pontapé de saída educativo", acrescenta Engrácio (2008, p. 69).

Os resultados da empatia em sala de aula, porém, estão muito ligados ao talento do professor para utilizar o humor com fins didáticos, necessitando sempre que suas estratégias de ensino, humorísticas ou não, sejam multifacetadas e que não acabem tendo a função de um mero transmissor de conhecimentos. "Este empenho e preparação contínuos podem mesmo ser vistos

4 "I remember attending lectures with many teachers. However, I enjoyed only a few of these classes. Upon reflection, I realised that the classes I truly enjoyed were led by teachers who incorporated humour in their teaching." (ABU BAKAR, 2018, p. 3). 


\section{Penista Leteas Paras \\ ISSN: 2317-2347 - v. 10, n. 4 (2021) \\ Todo o conteúdo da RLR está licenciado sob Creative Commons Atribuição 4.0 Internacional}

como o ensaio de um actor que procura a melhor performance no 'palco' que é a sala de aula. Ser professor é assim uma forma de arte." (ENGRÁCIO, 2008, p. 71).

Tendo isso em vista, é importante considerar o tipo de humor que será selecionado, não sendo qualquer tipo de piada que pode ser agregadora de conhecimento para a turma de alunos:

Berk [2002] aconselha que vários tipos de humor devem ser deixados fora da sala de aula por serem de algum modo hostis e não fomentarem a empatia. Assim, considera que estilos humorísticos como a ridicularização, o sarcasmo, a vulgaridade ou a humilhação são desnecessários e contraproducentes. 0 estudo de Webb [2001] revelava que, mais de 7 em cada 10 alunos e professores entende que não se deve usar o humor de modo depreciativo, humilhando ou ridicularizando os alunos. O problema é que uma grande maioria das situações humorísticas envolve alguma destas características. Basta visualizar os anúncios na televisão, as piadas dos filmes e séries, da Stand Up Comedy ou ainda os cartoons políticos. À nossa volta parece que 0 humor mais presente é aquele que emana da boa velha teoria da superioridade de Platão, Aristóteles e de Hobbes. (ENGRÁCIO, 2008, p. 66)

Desse humor problemático nas escolas e universidades, podem ser listados vários casos noticiados em jornais e revistas e denunciados por alunos à direção escolar. Um exemplo claro disso foi relatado por alunos da Pontifícia Universidade Católica do Rio Grande do Sul (PUCRS), onde um docente em aula teria dito "leis são como mulheres, feitas para serem violadas" (SUPOSTA..., 2015, on-line). Outro caso aconteceu na Ufac, onde as piadinhas machistas de um professor fizeram com que as alunas do curso de jornalismo espalhassem cartazes com os dizeres "Professor, sua piada machista não faz de você engraçado, faz de você apenas mais um babaca graduado" (ACADÊMICAS..., 2016, on-line). Já na Faculdade de Agronomia da Universidade Federal do Rio Grande do Sul, o relato é de racismo: um professor de Leguminosas de Grãos Alimentícios, em sua primeira aula da disciplina no semestre, disse que "os negrinhos da favela só tinham os dentes brancos porque a água que bebiam possuía flúor" (PROFESSOR..., 2009, on-line) e "soja é que nem negro, uma vez que nasce é difícil de matar" (PROFESSOR..., 2009, on-line). Essa atitude foi analisada por uma comissão de sindicância na faculdade que considerou que o professor tinha "o intuito de criar um ambiente mais descontraído no primeiro dia de aula" (PROFESSOR..., 2009, on-line). Posteriormente, o professor foi condenado pelo Tribunal Regional Federal da 4ª Região (PROFESSOR..., 2009, on-line). Isso para relatar apenas casos noticiados pela imprensa, pois fora dela os casos podem ser incontáveis. Percebe-se, portanto, que

a liberdade humorística do professor não é tão extensa como a do cómico dado que há tipos de humor que são nitidamente prejudiciais na sala de aula. E para além disso, o professor não deve destilar as mesmas quantidades de humor já que a sua função não é fazer rir, por si só, mas usar o humor como auxiliar na explicação da matéria. (ENGRÁCIO, 2008, p. 73) 


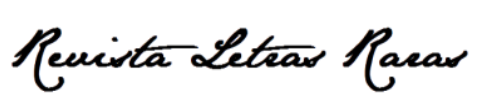

ISSN: 2317-2347 - v. 10, n. 4 (2021)

Todo o conteúdo da RLR está licenciado sob Creative Commons Atribuição 4.0 Internacional

Outra perspectiva de pesquisa que se volta para o ponto de vista não apenas dos professores em relação ao riso em sala de aula, mas também ao dos alunos é a de Farhana Abu Bakar (2018). Essa autora discorre que ainda são poucas as pesquisas que dão voz aos alunos, sendo em geral apenas professores analisando o humor utilizado por eles próprios e os resultados que obtiveram. Abu Bakar afirma que de 45 artigos que analisou apenas 19 se detiveram na perspectiva dos alunos e apenas 3 se concentraram na perspectiva de ambos (ABU BAKAR, 2018). A partir disso, essa pesquisadora delineou outra trilha investigativa: entrevistou 15 estudantes e 5 professores citados pelos alunos como professores que se utilizam do humor. Nenhum dos estudantes entrevistados relatou pontos negativos no humor em sala, apontando que isso os ajudou a aumentar o foco, a motivação e a habilidade em lembrar do conteúdo da matéria. Ao serem questionados sobre o que se lembravam em relação às aulas nas quais o professor intercalava o conteúdo com comentários engraçados, cada aluno conseguiu descrever, no mínimo, uma das piadas utilizadas pelo professor e fazer a sua devida relação com o conteúdo estudado. Além disso, o estímulo provocado pela comicidade seria ainda uma alternativa de manter os alunos distantes de distrações como celular, notebook, dentre outros eletrônicos (ABU BAKAR, 2018).

Marcela Fontes (2014), em sua pesquisa intitulada Riso, humor e resistência na escola pública de ensino fundamental, estuda as formas de resistência de intencionalidades críticas desenvolvidas pelos alunos a fim de afirmar o seu lugar dentro de sala de aula, barrar a dominação de professores e não perder sua identidade e costumes. Tomando essa perspectiva, Fontes (2014) analisa como o humor empregado pelos alunos pode vir a ser uma forma de resistência constituindo comportamentos diferenciados dos objetivos acadêmicos. Com isso, as expressões de humor dos alunos acabam virando motivo de descontentamento de professores que passam a vê-las com maus olhos. Nas palavras de Fontes:

Na maior parte das vezes, o riso na escola ocorre nos interstícios do pensamento sério e de maneira extraoficial, ou seja, em uma rede de comunicação paralela empreendida pelos alunos. Já a rede de comunicação principal, empreendida pelo professor por meio de um discurso oficial e sério, na maior parte das vezes, não admite a insolência do riso. (FONTES, 2014, p. 31)

Sua investigação consistiu em entrevistas de alunos do nono ano e teve resultados semelhantes à de Abu Bakar (2018), com apenas dois alunos dizendo que acreditavam não aprenderem mais com o uso de piadas pelo professor, mas que isso fazia com que houvesse uma distração, o que era bom. "Só seriedade e seriedade acaba ficando ruim" (FONTES, 2014, p. 102), afirma um deles. 


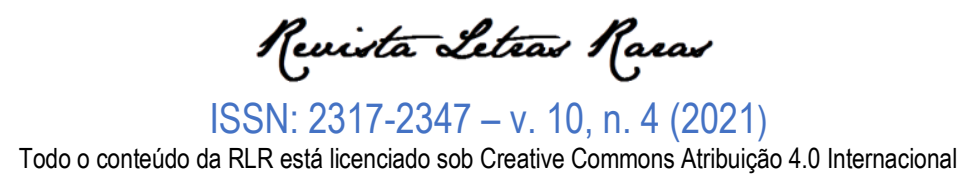

As pesquisas sobre o assunto ainda tomam rumos mais específicos, com foco na aplicabilidade do humor em sala de aula em diferentes disciplinas.

Bruno Oliveira Lima (2017), por exemplo, direciona seu trabalho para o estudo do humor no ensino da biologia. Sua metodologia de pesquisa consistiu em um questionário feito aos alunos de ensino médio da cidade de Campina Grande que participaram dos "aulões" de biologia preparatórios para o Exame Nacional do Ensino Médio (ENEM) de 2016. Ele justifica a metodologia partindo do pressuposto de que o "conhecimento sobre os indivíduos só é possível com a descrição humana, tal como ela é vivida e definida pelos seus próprios atores" (LIMA, 2017, p. 55). Ao fazer um levantamento dos resultados da pesquisa, relata:

Analisando os dados, percebemos que $88 \%$ dos participantes relataram que os "aulões" de Biologia com caráter humorístico ajudaram bastante a serem aprovados no exame de vestibular/ENEM. Para $12 \%$ deles, só ajudaram um pouco, e nenhum participante respondeu que não ajudou. Os alunos que responderam "ajudou pouco" tinham participado de menos de três encontros durante 0 ano. (LIMA, 2017, p. 62)

Já no campo da química se destaca a pesquisa de Erik Benedicto (2013). Nela, ele discorre sobre o uso de cartuns com a temática ciência (existentes desde o século XVIII com um viés pejorativo) e como os químicos, a partir do século XX, começaram eles próprios a fazer seus cartuns, relacionando aos conceitos da área. "Os autores defendem o uso deste tipo de material para aperfeiçoar o ensino, mas destacando o cuidado na seleção do cartum a ser utilizado e as imagens que este pode transmitir" (BENEDICTO, 2013, p. 36). O autor destaca ser importante a presença de charadas e anedotas, acionando positivamente os conceitos da área como os trocadilhos a fim de produzir efeito cômico. Como exemplo ele cita anedotas: "O que dez carbonos estavam fazendo numa escada? Deceno" (BENEDICTO, 2013, p. 36), "O metil e o metano foram pular de paraquedas. Quem pulou primeiro? O metil, porque ele é radical" (BENEDICTO, 2013, p. 36), dentre outras que se tornaram populares através da internet (BENEDICTO, 2013). Erik Benedicto ressalta ainda a demanda dos alunos por mais aulas práticas na disciplina, tornando 0 conhecimento estudado mais "palpável", o que revela descontentamento e cansaço com as típicas aulas com esquemas tradicionais (BENEDICTO, 2013). ${ }^{5}$

No campo do humor como uma estratégia pedagógica possível para as aulas de língua portuguesa, os materiais são muitos. Rosani Muniz Marlow (2017), em seu artigo intitulado Piada

5 "É bastante comum entre os professores de química utilizar piadas nas aulas de forma que a aprendizagem se efetive. Uma piada clássica é aquela que o professor de química está fazendo chamada oral para um aluno. Então pergunta: "- $\mathrm{O}$ que é H2SO4?". O aluno demora a responder. E, depois de alguns minutos de silêncio, arrisca: "Professor, está na ponta da língua, mas eu não consigo dizer.”. O professor gozador responde: "- Então, cospe logo, porque é ácido sulfúrico!". (VASCONCELOS, 2019, p. 179). 


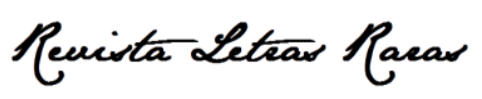

ISSN: 2317-2347 - v. 10, n. 4 (2021)

Todo o conteúdo da RLR está licenciado sob Creative Commons Atribuição 4.0 Internacional

em sala de aula é coisa séria: o potencial dos textos chistosos para o ensino de língua portuguesa, apresenta uma perspectiva do ensino de língua portuguesa nas escolas de ensino básico por meio da problematização das práticas de alfabetização e letramento empregadas pelos professores há décadas. Analisando os Parâmetros Curriculares Nacionais (PCN) de 1997, ela destaca a necessidade de práticas pedagógicas sociais que "promovam aos alunos o uso eficaz da linguagem: a compreensão ativa - e não a decodificação e o silêncio - e o uso da fala e da escrita como expressão e comunicação por meio de textos - e não a avaliação da correção do produto" (MARLOW, 2017, p. 56). Ao discorrer sobre os altos índices de evasão escolar de crianças e adolescentes, a autora reitera a necessidade de aproximar o conhecimento que o aluno já dispõe ao que vai ser ensinado:

A aprendizagem ocorre quando 0 aluno participa ativamente do processo de construção do conhecimento, aplicando seus esquemas operatórios de pensamento aos conteúdos estudados. Ou seja, aprender é uma atividade mental, é pensar, refletir e agir. A aprendizagem será favorecida quando forem substituídas as tarefas "mecânicas", que apelam para a repetição e a memorização, por outras tarefas que estimulem e exijam dos alunos a execução de operações mentais. (MARLOW, 2017, p. 58)

A filiação a uma pedagogia que valorize a voz, a experiência e a vivência dos alunos, também afinada com contribuições freireanas, é defendida por bell hooks $(2017)^{6} \mathrm{em}$ seu livro Ensinando a transgredir: a educação como prática de liberdade ${ }^{7}$, onde fala da sua experiência como professora e da importância que tem para ela o papel do professor como alguém que ensina os alunos a "transgredir" fronteiras raciais, sexuais e de classe. Nele, hooks (2017) afirma:

Todos os alunos, não somente os de grupos marginalizados, parecem mais dispostos a participar energeticamente das discussões em sala quando percebem que elas têm uma relação direta com eles (se os alunos são brancos só falam na sala quando se sentem ligados ao tema pela experiência, esse comportamento não é aberrante). Os alunos, mesmo quando versados num determinado tema, podem ser mais tendentes a falar com confiança quando ele se relaciona diretamente com sua experiência. (HOOKS, 2017, p. 118)

Para Rosani Marlow (2017), o uso do humor por meio do gênero discursivo piada nas aulas de língua portuguesa colaboraria com a aproximação do conhecimento dos alunos com as práticas de letramento das aulas, visto o grande aumento da circulação de textos humorísticos após a popularização de redes sociais e dos ambientes virtuais. Esse aumento da produção de informação do uso decorrente da internet possibilitou o surgimento de novos gêneros discursivos

\footnotetext{
6 Em letras minúsculas mesmo!

7 Também em letras minúsculas na capa do livro.
} 


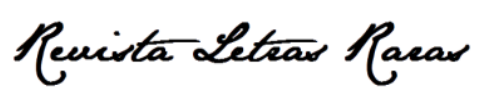

ISSN: 2317-2347 - v. 10, n. 4 (2021)

Todo o conteúdo da RLR está licenciado sob Creative Commons Atribuição 4.0 Internacional

que podem ser trabalhados em sala e que ainda permitiriam o aprofundamento de outras temáticas como marcas de oralidade, intertextualidade e questões sociais.

Sírio Possenti (2001) também defende a importante colaboração da piada para os estudos sociais e principalmente para o estudo da língua. Em O humor e a língua, Possenti (2001) apresenta vários exemplos de piadas e de jogadas de duplo sentido, intencional ou não, que podem ser aproveitadas para além do seu conteúdo humorístico e abordadas a partir da perspectiva linguística. Em outro texto, intitulado Os limites do humor, Possenti afirma:

No entanto, além de representarem ou exporem fatos e comportamentos sociais, mesmo que o façam indiretamente, as piadas levam a língua a seus limites também nos domínios da gramática, e não apenas do léxico.

Diria que, do ponto de vista da língua, os fenômenos mais interessantes não são ligados à exploração do léxico, especialmente no que se refere a questões de etiqueta e a certas conotações. As piadas exploram outros fatos da linguagem, que têm mais a ver com limites da gramática (léxico, morfologia, sintaxe e semântica) e mesmo das assim chamadas regras pragmáticas do que com questões de finesse. Talvez não seja descabido dizer que as piadas jogam (também no sentido de divertir-se, mas, principalmente, de mobilizar regras...) com as aparentes regularidades gramaticais. Mais: além de levar a língua a seus limites, as piadas exigem uma precisa seleção de elementos não-linguísticos, contextuais ou intertextuais. (POSSENTI, 2003, p. 104, grifos do autor)

Já Hélio de Sant'Anna dos Santos (2010) propõe trabalhar o humor nas aulas de língua portuguesa a partir da literatura. Em seu artigo A contribuição do trabalho com o humor para 0 ensino de língua portuguesa, discorre a respeito das possibilidades de desenvolvimento de habilidades de leitura nos alunos a partir do livro Comédias da vida privada - edição especial para escolas, de Luis Fernando Verissimo. Esse livro contém uma série de crônicas humorísticas que podem servir de base para o estudo de interpretação do texto além de abrir espaço para reflexões mais profundas sobre os recursos textuais no meio escrito, pois o texto de humor, em geral, contém jogos linguísticos (fonéticos, morfológicos ou sintáticos) ${ }^{8}$, metáforas, comparações e sinais de pontuação especiais. Isso significa que o texto humorístico estimula um mergulho nos fios do texto, já que, conforme enuncia Pereira,

Quando "tomamos" um texto (é tomar mesmo, apropriar-se, apossar-se), é preciso percebê-lo inteiro, nas suas estruturas mais profundas, na sintaxe que o formou, na morfologia que o moldou, na semântica que lhe deu sentido e nas palavras selecionadas para tal. 0 adjetivo não só define ou qualifica. É para que se entenda por que está ali, qual o seu valor, sua contribuição para 0 resultado final do texto. $O$ ponto de exclamação não é só para se admirar, nem

\footnotetext{
8 Um exemplo é a piada jocosa e preconceituosa com base na articulação fonética de um enunciado envolvendo uma jogadora de vôlei, nascida no interior do estado de São Paulo, cuja marca é a vibrante múltipla retroflexa. A cena é a seguinte: 0 juiz da partida de vôlei diz para a jogadora: "- Fulana, once more." (que significa mais uma vez). Ela responde: "- Em Piracicaba." (porque entende "onde cê mora?").
} 


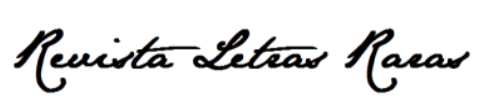

ISSN: 2317-2347 - v. 10, n. 4 (2021)

Todo o conteúdo da RLR está licenciado sob Creative Commons Atribuição 4.0 Internacional

para caracterizar a surpresa, mas para contribuir para a sintaxe, para o ritmo, para o sentido geral. (PEREIRA, 1999, p. 220, grifo do autor apud SANTOS, 2010, p. 233)

A abordagem desse tipo de texto em sala propõe tornar 0 ato de ler mais divertido e agradável a fim de tentar aproximar dos livros estudantes que não têm o hábito de leitura. Nesse sentido, eles podem perceber que a leitura pode ser muito prazerosa e pode servir de porta para novos interesses literários. Santos (2010) conclui seu artigo, sugerindo diversas formas de abordagem das crônicas do livro de Verissimo nas aulas de língua portuguesa, o que pode servir de ponto de partida para muito professores.

Seguindo a proposta de motivar professores de língua portuguesa a trabalhar o humor com seus alunos, Clediane Santos (2013) desenvolve uma unidade didática para professores que ministram aulas para alunos e alunas do oitavo ano do ensino fundamental. Nessa unidade didática, a partir da exposição de variados contos de humor, ela propõe atividades que possam ser desenvolvidas com os estudantes, tanto de interpretação de texto e de desenvolvimento das capacidades leitoras, como também de produção textual inspirada nos contos trabalhados, como, por exemplo, escrever um conto que retrate uma situação cômica vivida pelos alunos. É imprescindível, porém, que deva ser levado em consideração o público-alvo do projeto proposto, sendo analisado o "nível de leitura em que o aluno esteja inserido, pois cada texto exige uma série de requisitos para que seja interpretado", conforme alerta Hélio de Sant'Anna Santos (2010, p. 234).

Maria Aparecida Resende Ottoni (2007) concentra sua pesquisa nos gêneros do humor no ensino de língua portuguesa e afirma existirem atualmente mais pesquisas centradas no ensino de atividades de leitura e escrita, tendo o humor como mote central do que tempos atrás:

Alguns/mas investigadores/as desenvolvem seus trabalhos focalizando gêneros do humor específicos; outros/as enfocam o uso do humor em geral no ensino. Trachtenberg (1980), Vadillo (1998) e Berti (2002), por exemplo, centram-se nas piadas; Smith (2000), nos cartuns; Pereira (2003), nas tiras; Pavei (2005), nas charges; Araújo (2001), nos cartuns e charges; Silva (2005), nas charges e tiras. Já Garner (2005), Kher, Molstad e Donahue (1999) e Powers (2005) argumentam em favor do humor em geral no ensino. (OTTONI, 2007, p. 167)

Entretanto, complementa a autora, a maioria dessas pesquisas apresenta lacunas teóricas e metodológicas no trabalho com o humor em sala de aula. Muitos dos trabalhos levantados por ela são somente sugestões de como os professores podem utilizar o humor em sala de aula, sendo que muitas das sugestões nem haviam sido testadas em sala (OTTONI, 2007).

Em sua pesquisa, Ottoni (2007) também aborda alguns dos pontos de vista contrários à utilização de comicidade ou do humor na educação. Entre os argumentos citados está o de Van 


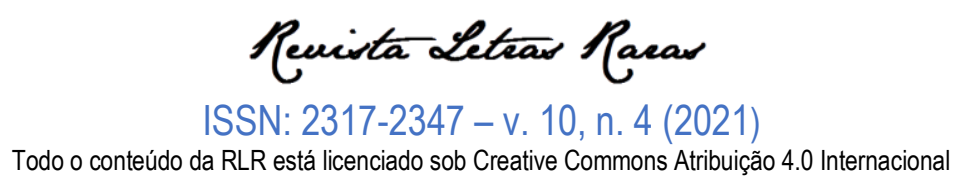

Tassel (2013 apud OTTONI, 2007), que, ao discorrer sobre o fato de que o humor amenizaria as relações de hierarquia entre alunos e professores, atesta que isso não é algo desejado. Para Van Tassel (2013 apud OTTONI, 2007), isso poderia implicar a recusa dos alunos em estudar o que Ihes é apresentado pelo professor, transformando a sala de aula em uma disputa de autoridade. Outro argumento citado por ela é o medo do professor de lidar com o que os pais, diretor e outros professores pensariam ao ver sua turma inteira rindo. "Há uma valorização do que se chama 'tempo ocupado', em que os estudantes 'parecem' estar aprendendo" (OTTONI, 2007, p. 168). Ottoni, apoiada em Bauer (1996 apud OTTONI, 2007), afirma que os professores não sabem lidar com o gênero humor e que têm medo de que isso lhes possa trazer embaraço. Outro ponto levantado pelos autores que Ottoni (2007) cita é a subjetividade presente no humor: o que uns acham engraçado, outros podem não achar. Isso influenciaria negativamente o uso da comicidade ou do humor em sala de aula. "O humor pode agir como um lubrificante social ou como um 'retardador' social no cenário educacional. Ele pode educar ou 'desfigurar'." (LOOMANS; KOLBERG, 1993, p. 14 apud OTTONI, 2007, p. 169).

Apesar disso, Ottoni (2007) diz não terem sido esses argumentos suficientes para mudar sua motivação em relação a "incentivar a leitura e análise crítica de textos de gêneros do humor em sala de aula" (OTTONI, 2007, p. 169). Mesmo assim, ela desenvolve sua pesquisa onde, ao final, faz uma análise dos pontos positivos e negativos na aplicação de sua proposta para os alunos. Dentre os pontos negativos, ela cita a indisciplina e o excesso de conversas paralelas durante a abordagem do tema e durante a proposta das atividades. Porém, Ottoni (2007) ressalta serem esses problemas aliados à desmotivação a maior dificuldade enfrentada pelos professores atualmente. Segundo ela, a causa da indisciplina, contudo, seria motivada por fatores externos, tais como a falta de limites impostos pela família dos alunos, pela comunidade e pela escola.

Como se vê, trata-se de questões maiores que não dizem respeito apenas ao desenvolvimento da P.F. [Proposta Final], mas à situação da educação como um todo no Brasil e a questões sociais. Para resolvê-las penso que é necessário muito mais que os esforços de professores/as/ pesquisadores/as. (OTTONI, 2007, p. 252)

É importante salientar que os resultados obtidos a partir do uso de diversas estratégias de ensino e aprendizagem não dependem somente do interesse do professor em aplicá-las ou não. É de suma importância levar em consideração, primeiramente, o ambiente em que a aula é ministrada, suas condições estruturais, o tamanho das turmas, condições ergonômicas, condições sociais dos estudantes, "motivações, expectativas, convicções, conhecimentos, relação entre si, assim como o contexto e a relação com o professor" (ENGRÁCIO, 2008, p. 64). Ao propor 


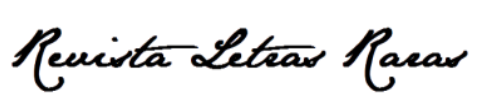

ISSN: 2317-2347 - v. 10, n. 4 (2021)

Todo o conteúdo da RLR está licenciado sob Creative Commons Atribuição 4.0 Internacional

metodologias que envolvam humor, tenta-se, além de manter a atenção dos alunos e obter melhores resultados na aprendizagem, contornar situações adversas na educação, como uma forma de tentar manter o otimismo e a inspiração dos estudantes. Cabe ressaltar, por fim, a importância de se ter em vista que a aprendizagem não é uma via de mão única da qual somente o professor faz parte. $O$ aluno é um agente importante dentro do processo, cabendo também a ele ser parte viva na busca por melhores resultados.

\section{Considerações finais}

A partir da pesquisa bibliográfica realizada, percebe-se a variada gama de estudos que atualmente está surgindo sobre o uso do humor na educação e os diversos benefícios ao aprendizado e à sociabilidade que ele pode conferir, além de questões possivelmente problemáticas em seu uso no espaço escolar. Junto a isso, o humor ainda pode servir não apenas como um desvio cômico ou um artifício de manter os alunos prestando atenção à aula, mas também como um efetivo tema no estudo de gêneros discursivos em língua portuguesa. Ademais, vê-se que as possibilidades de uso do humor como estratégia pedagógica não se aplicam somente a disciplinas específicas, mas que podem ser desenvolvidas nas mais variadas situações e metodologias de ensino.

Apesar disso, é necessária uma análise prévia das piadas ou dos fatos ou dos textos humorísticos para verificar se vêm realmente para colaborar com a dinâmica da aula. Chistes ofensivos, inconvenientes, com teor sexual, sexista, de gênero ou racial que de algum modo possam ser mal interpretados pelos alunos devem ficar de fora do plano de aula. É necessário que muito se analise como o humor auxiliará no aprendizado e até que ponto ele não será apenas um causador de dispersão dentro de sala de aula.

Com isso, espera-se ter conseguido nortear pesquisadores que tenham interesse pelo tema e que queiram se aprofundar mais na vasta bibliografia disponível, da qual uma pequena parte foi exposta. Apesar de plena consciência das inúmeras limitações enfrentadas pelos professores em sala de aula, espera-se que os resultados parciais da pesquisa que ora se apresentam aqui possam ao menos inspirar educadores a investigar outras formas de trabalhar conteúdos em suas aulas, não se limitando a esquemas estabelecidos sérios e sisudos. 


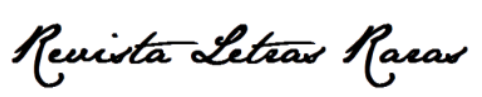

ISSN: 2317-2347 - v. 10, n. 4 (2021)

Todo o conteúdo da RLR está licenciado sob Creative Commons Atribuição 4.0 Internacional

Como perspectiva de estudos ou de propostas futuras do uso do humor em práticas pedagógicas, outra vertente pode ser abordada: a dos memes em aulas de línguas, como as pesquisas de Souza (2019) e de Souza, Nóbrega e Lima Júnior (2019), por exemplo.

\section{CRediT}

Reconhecimentos: Não é aplicável.

Financiamento: Não é aplicável.

Conflitos de interesse: Os autores certificam que não têm interesse comercial ou associativo que represente um conflito de interesses em relação ao manuscrito.

Aprovação ética: Não é aplicável.

Contribuições dos autores:

Conceitualização, Análise formal, Investigação, Metodologia, Administração do projeto, Visualização, Escrita rascunho original, Escrita - revisão e edição: VASCONCELOS, Silvia Ines Coneglian Carrilho de.

Conceitualização, Análise formal, Investigação, Metodologia, Administração do projeto, Visualização, Escrita rascunho original, Escrita - revisão e edição: DELLAI, Érica Milani.

\section{Referências}

ABU BAKAR, Farhana. The use of humour in teaching and learning in higher education. 2018. 193 f. Tese (Doutorado em Filosofia) - University of Otago, Dunedin-New Zealand, 2018. Disponível em: https://ourarchive.otago.ac.nz/handle/10523/8238. Acesso em: 5 mar. 2021.

ACADÊMICAS da Ufac protestam contra professor que faz piadas machistas. 3 de Julho Notícias, Acre, 7 jul. 2016. Educação. Disponivel em: https://3dejulhonoticias.com.br/educacao/academicas-da-ufac-protestam-contra-professor-quefaz-piadas-machistas/. Acesso em: 25 jun. 2019.

ALBERTI, Verena. O riso e o risível na história do pensamento. Rio de Janeiro: Jorge Zahar; Ed. FGV, 1999.

ARANHA, Maria Lúcia de Arruda. História da educação e da pedagogia geral e do brasil. São Paulo: Moderna, 2006.

BAKHTIN, Mikhail. A cultura popular na idade média e no renascimento. Tradução de lara Frateschi Vieira. São Paulo: Hucitec, 1999.

BENEDICTO, Erik Ceschini Panighel. Humor no ensino de química. 2013. 114 f. Dissertação (Mestrado em Química Analítica e Inorgânica) - Universidade de São Paulo, São Carlos, 2013. Disponível em: https://www.teses.usp.br/teses/disponiveis/75/75135/tde-24022014-114947/ptbr.php. Acesso em: 5 mar. 2021.

BERGSON, Henri. O riso: ensaio sobre a significação do cômico. Tradução de Nathanael C. Caixeiro. Rio de Janeiro: Jorge Zahar, 1983.

ENGRÁCIO, Handerson Aguiar. O humor na educação. 2008. 129 f. Dissertação (Mestrado em Comunicação Educacional Multimédia) - Universidade Aberta, Lisboa, Portugal, 2008. 


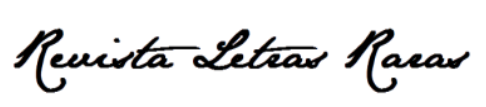

ISSN: 2317-2347 - v. 10, n. 4 (2021)

Todo o conteúdo da RLR está licenciado sob Creative Commons Atribuição 4.0 Internacional

FONTES, Marcela Goulart. Riso, humor e resistência na escola pública de ensino fundamental: a perspectiva dos alunos. 2014. 168 f. Dissertação (Mestrado em Educação) - Universidade Federal de São João Del-Rei, São João Del-Rei, MG, 2014.

FREIRE, Paulo. Pedagogia do oprimido. São Paulo: Paz e Terra, 1974.

FREIRE, Paulo. Pedagogia da esperança: um reencontro com a pedagogia do oprimido. São Paulo: Paz e Terra, 1992.

FREUD, Sigmund. O chiste e sua relação com o inconsciente (1905). Tradução de Fernando Costa Mattos e Paulo César de Souza. São Paulo: Companhia das Letras, 2017. (Obras completas, v. 7).

HOOKS, bell. Ensinando a transgredir: a educação como prática de liberdade. Tradução de Marcelo Brandão Cipolla. 2. ed. São Paulo: WMF Martins Fontes, 2017.

JOSÉ, Helena Maria Guerreiro. Resposta humana ao humor: quando o humor integra o agir profissional dos enfermeiros. 2008. 319 f. Tese (Doutorado em Enfermagem) - Universidade de Lisboa, Lisboa, 2008. Disponivel em: https://bdlb.bn.gov.br/acervo/handle/20.500.12156.3/180702. Acesso em: 5 mar. 2021.

LARROYO, Francisco. História geral da pedagogia. Tradução de Luiz Aparecido Caruso. 2. ed. São Paulo: Ed. Mestre Jou, 1974. t. 1.

LIMA, Bruno Oliveira de. Humor e teoria de flow: uma forma inovadora de ensinar biologia. 2017. 91 f. Dissertação (Mestrado em Ensino de Ciências e Educação Matemática) - Universidade Estadual da Paraíba, Campina Grande, 2017. Disponível em: http://tede.bc.uepb.edu.br/jspui/handle/tede/3198. Acesso em: 5 mar. 2021.

MARLOW, Rosani Muniz. Piada em sala de aula é coisa séria: o potencial dos textos chistosos para o ensino de língua portuguesa. PERcursos Linguísticos, Vitória, v. 7, n. 15, p. 55-73, 2017. Disponível em: http://periodicos.ufes.br/percursos/article/view/15597/11992. Acesso em: 11 jun. 2019.

MINOIS, Georges. História do riso e do escárnio. Tradução de Maria Elena Ortiz Assumpção. São Paulo: Ed. Unesp, 2003.

OTTONI, Maria Aparecida Resende. Os gêneros do humor no ensino de língua portuguesa: uma abordagem discursiva crítica. 2007. 399 f. Tese (Doutorado em Linguística) - Universidade de Brasília, Brasília, 2007. Disponível em: https://repositorio.unb.br/handle/10482/1999. Acesso em: 5 mar. 2021.

POSSENTI, Sírio. O humor e a língua. Ciência Hoje, [s. I.], v. 30, n. 176, p. 72-74, 2001. Disponível em: $\quad$ http://aescritanasentrelinhas.com.br/wp-content/uploads/2009/02/o-humor-e-a-linguatexto.pdf. Acesso em: 11 jun. 2019.

POSSENTI, Sírio. Os limites do humor. Letras, Santa Maria, n. 26, p. 103-110, 2003. Disponível em: https://periodicos.ufsm.br/letras/article/view/11885/7312. Acesso em: 11 jun. 2019.

PROFESSOR é condenado por fazer piada racista. Consultor Jurídico, São Paulo, 18 maio 2009. Disponivel em: https://www.conjur.com.br/2009-mai-18/professor-condenado-piada-racista-salaaula. Acesso em: 25 jun. 2019.

PROPP, Vladmir. Comicidade e riso. Tradução de Aurora Fornoni Bernardini e Homero de Freitas de Andrade. São Paulo: Ática, 1992. 


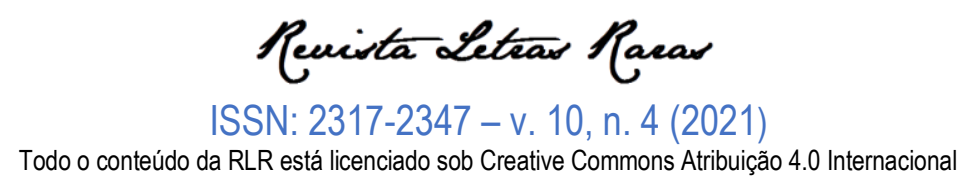

RISO. In: DICIONÁRIO on-line Michaelis. [S. I.]: Melhoramentos, 2015. Disponível em: http://michaelis.uol.com.br/moderno-portugues/busca/portugues-brasileiro/riso/. Acesso em: 10 jun. 2019.

RISO. In: ENCICLOPÉDIA Barsa Universal. São Paulo: Planeta, 2010. v. 15, p. 5.258.

SANTOS, Clediane Aparecida Ferreira dos. Contos de humor como instrumento para desenvolver a compreensão leitora e a produção textual. Os desafios da escola pública paranaense na perspectiva do professor PDE: produções didático-pedagógicas. Paraná: Secretaria de Educação, 2013. v. 2, [p. 1-21].

SANTOS, Hélio de Sant'Anna dos. A contribuição do trabalho com o humor para o ensino de língua portuguesa. Miscelânea, Assis, v. 8, p. 226-239, jul./dez. 2010. Disponível em: http://seer.assis.unesp.br/index.php/miscelanea/article/view/658/623. Acesso: 12 jun. 2019.

SILVA, Kamylla Rodrigues Pereira da; CAMPOS, Rafael dos Santos. Risos consentidos: 0 ato de rir no processo ensino-aprendizagem. In: CONGRESSO NACIONAL DE EDUCAÇÃO, 1., 2014, Campina Grande. Anais I CONEDU. Campina Grande-PB: Ed. Realize, 2014, [p. 1-5]. Disponível em: http://www.editorarealize.com.br/artigo/visualizar/7932. Acesso em: 24 jun. 2019.

SOUSA, Luis Manuel Mota. Benefícios do humor na saúde: revisão sistemática de literatura. Enformação, Portugal, p. 22-32, jan./jun. 2016. Disponível em: http://repositorio.chlc.minsaude.pt/bitstream/10400.17/2584/1/enformacao_07_2016\%2022\%2032.pdf. Acesso em: 24 jun. 2019.

SOUZA, Fabio Marques de. A análise e a produção de memes como atividade mediadora do complexo processo de ensino-aprendizagem de inglês. In: SOUZA; Fábio Marques de; SANTOS, Geyza de Freitas. Velhas práticas em novos suportes? As tecnologias digitais como mediadoras do complexo processo de ensino-aprendizagem de línguas. São Paulo: Mentes Abertas, 2019. p. 113-121.

SOUZA, Fabio Marques de; NÓBREGA, Daniela Gomes de Araújo; LIMA JÚNIOR, Celso José. Os memes como possíveis mediadores do complexo processo de ensino-aprendizagem de línguas adicionais. In: SOUZA, Fabio Marques de et ali (org.). Ensino de línguas na contemporaneidade: culturas, tecnologias e alteridades. São Paulo: Mentes Abertas, 2019. p. 97-114.

SUPOSTA piada machista de professor repercute em universidade do RS. G1, Rio Grande do Sul, 24 abr. 2015. Disponível em: http://g1.globo.com/rs/rio-grande-do-sul/noticia/2015/04/supostapiada-machista-de-professor-repercute-em-universidade-do-rs.html. Acesso em: 25 jun. 2019.

VASCONCELOS, Silvia Ines Coneglian Carrilho de. O dispositivo humorístico no ensino de português como língua estrangeira. In: VASCONCELOS, Silvia Ines Coneglian Carrilho de (org.). Práticas pedagógicas e material didático no ensino de português como língua não materna. São Carlos, SP: Pedro e João Editores, 2019. p. 177-189.

VASCONCELOS, Silvia Ines Coneglian Carrilho de (org.). Ludicidade no ensino de português como língua materna e não materna. São Paulo: Mentes Abertas, 2021. 